\title{
Adaptation assessments for crop production in response to climate change in Cameroon
}

\author{
Munang TingeM ${ }^{1 *}$, Mike RIVINGTON $^{2}$, Gianni BeLLOCCHI $^{3}$ \\ ${ }^{1}$ Agriculture \& Environmental Science Division, School of Bioscience, University of Nottingham, NG7 2RD, UK \\ ${ }^{2}$ Macaulay Institute, Craigiebuckler, Aberdeen, AB15 8QH, Scotland \\ ${ }^{3}$ Agrichiana Farming - Montepulciano, Italy
}

(Accepted 8 October 2008)

\begin{abstract}
The Cameroonian agricultural sector, a critical part of the local ecosystem, is potentially vulnerable to climate change, thus raising concerns about food security in the country's future. Adaptations policies may be able to mitigate some of this vulnerability. This article addresses the issue of selected adaptation options within the context of Cameroonian food production. A methodology is applied where transient diagnostics of two atmosphere-ocean general circulation models, the NASA/Goddard Institute GISS and the British HadCM3, are coupled to a cropping system simulation model (CropSyst). This methodology simulates current and future (2020, 2080) crop yields for selected key crops such as bambara nut, groundnut, maize, sorghum, and soybean, in eight agricultural regions of Cameroon. Our results show that for the future, substantial yield increases are estimated for bambara groundnut, soybean and groundnut, while little or no change or even decreases for maize and sorghum yields, varying according to the climate scenario and the agricultural region investigated. Taking the "no regrets" principle into consideration, we also explore the advantages of specific adaptation strategies specifically for three crops, maize, sorghum and bambara groundnut, under GISS A2 and B2 marker scenarios only. Here, changing sowing dates may be ineffective in counteracting adverse climatic effects because of the narrow rainfall band that strictly determines the timing of farm operations in Cameroon. In contrast, the possibility of developing later maturing new cultivars proved to be very effective in offsetting adverse impacts, giving the highest increases in productivity under different scenario projections without management changes. For example, under climate change scenario GISS A2 2080, a 14.6\% reduction in maize yield was converted to a $32.1 \%$ increase; a $39.9 \%$ decrease in sorghum yield was converted to a $17.6 \%$ increase, and for bambara groundnut, yields were almost trebled due to increase length of growing period and the positive effects of higher $\mathrm{CO}_{2}$ concentrations. These results better inform wider studies and development strategies on sustainable agriculture in the area by providing an indication as to the potential direction in shifts in production capabilities. Our approach highlights the benefit of using models as tools to investigate potential climate change impacts, where results can supplement existing knowledge. The findings also provide useful guidance and motivation to public authorities and development agencies interested in food security issues in Cameroon and elsewhere.
\end{abstract}

Cameroon / agriculture / climate change / policies / food security

\section{INTRODUCTION}

Climate change is one of the primary concerns for humanity in the 21 st century. The Intergovernmental Panel on Climate Change (IPCC) Fourth Assessment Report concludes that there is strong evidence that human activities have influenced the world's climate over the last century and a half (IPCC, 2007). Climate change effects are already being experienced.(Walther et al., 2002) and it is predicted that some extreme events will increase in frequency as a result of a change in natural climate variability (McCarthy et al., 2001).

Agriculture is inherently sensitive to climate conditions, and is one of the sectors most vulnerable to the risks and impacts of global climate change (Reilly, 1995; Smith and Skinner, 2002). A large amount of literature shows that without adaptation, climate change will be problematic in some regions (e.g. Cameroon, Tingem et al., 2008b) for agricultural production and communities. However, other studies suggest that detrimental climate impacts can be reduced and numerous opportunities can be created by changing climatic conditions (Smith and Wandel, 2006; Adger et al., 2005; Alexandrov and Hoogenboom, 2000; Bellocchi et al., 2002; Carbone et al., 2003; Gbetibouo and Hassan, 2004; Challinor et al., 2007a; Salinger et al., 2000). Climate extreme events will probably be the most challenging for farmers and society in general under future climate change (Rosenzweig et al., 2001).

* Corresponding author: m.tingem@googlemail.com 
Farmers in Cameroon have traditionally used indigenous knowledge to cope with climate hazards based upon observations and interpretation of natural phenomena. For example, the height of an ant nest in trees, or colour of frogs to make forecasts of the onset and cessation of the rainy season and quantity of rain (Molua, 2006). Crop choices, crop mixes and seasonal cropping calendars are largely based on these forecasts. Farmers' overriding concerns are meeting household needs, in particular achieving household food security. Harvesting natural products for food and income is considered a major and primary adaptation to climate hazards at the community level. However, land degradation (i.e. Onduru and Du Preez, 2007) and population growth coupled with climate change pose serious challenges on future food security in Cameroon and elsewhere. These challenges point to the need to realign and adopt new policies that contribute to greater resilience of the agricultural sector.

Previous research conducted in developing country settings indicate that, in principle, climate change impacts on agriculture can be reduced through human adaptations such as; adjusting sowing dates, changing cropping patterns (Mendelsohn et al., 1994; Rosenzweig and Hillel, 1998; Winters et al., 1998), or adopting higher-yielding and heat resistant cultivars, and improved extension services (Butt et al., 2005; Njie et al., 2006). To be effective, many of these adaptations, including spending on agricultural research and outreach programmes, and the selection and breeding of new hybrids and cultivars, would require an active role by government. It is important to recognise that changes in increasing atmospheric $\mathrm{CO}_{2}$ concentration and global warming are likely to alter the phenological response of certain crops, thereby putting current crop-weather relationships in doubt (Challinor et al., 2007b; Tingem et al., 2008b).

Although the breeding of new cultivars with improved yields under future climate is a potentially crucial adaptation option, the basis on which any new cultivars are developed will depend on the nature and extent of climate change in any specific region or cropping system. Crop simulation models that include the dynamics of crop-soil-weather interactions and integrate crop resource capture principles can assist plant breeding in the evaluation of the impact of specific traits on yield across a range of climates, soil types and seasons (Asseng et al., 2003).

This study uses both current and future climate scenarios, the latter from general circulation model (GCM) simulations, as inputs to a cropping system simulation model (CropSyst, Stöckle et al., 2003). The analysis performed in this paper addresses certain aspects of Article 4.1 of the United Nations Framework Convention on climate Change (UNFCCC) which commits countries to formulate and implement measures to facilitate adequate adaptation to climate change.

The general objective of this paper is to evaluate a set of adaptation options such as changes in sowing date and to investigate the importance of crop selection (maize (Zea mays L.), sorghum (Sorghum bicolor [L.] Moench) and bambara groundnut (Vigna subterranea [L.] Verdc) in the context of Cameroon agricultural systems.

\subsection{Cameroon: Background and vulnerability to climate change}

Cameroon is ranked 172 out of 229 countries in the world in terms of per capita income and nearly $40 \%$ of the population (6.8 million people) live on less that US $\$ 2$ per day (World Bank, 2007). The majority of the country's poor live in rural areas and work primarily in agriculture which is the largest sector of the economy contributing about $45 \%$ to the annual Gross Domestic Product (Molua and Lambi, 2006). Cameroon covers an area of about $475440 \mathrm{~km}^{2}$ between $2^{\circ}$ and $13^{\circ} \mathrm{N}$ with a population of $\sim 17$ million in 2006 . The area is characterized by highly contrasting physical features including $402 \mathrm{~km}$ of coastline and mountain ranges punctuated by peaks over $3000 \mathrm{~m}$.

The average temperature in Cameroon is predicted to increase as a result of global warming according to transient Global Circulation Models. Based on the HadCM3 model (Gordon et al., 2000; Johns et al., 2003), annual temperatures in Cameroon are expected to rise by 0.7 to $0.8{ }^{\circ} \mathrm{C}$ by the 2020s. The Goddard Institute for Space Studies (GISS) model (Hansen et al., 1998) projects double that increase in the same time period. Annual temperatures in the 2080 s are projected to increase relative to the baseline scenario (1961-1990) by 2.5 to $3.5^{\circ} \mathrm{C}$, and 3.1 to $4.4{ }^{\circ} \mathrm{C}$, according to the HadCM3 and GISS models respectively. Precipitation is expected to increase or decrease depending on the Global Circulation Model used. For the GISS and HadCM3 expected average \% changes in precipitation ranged between $-3.7 \%$ to $1.1 \%$ and $0.8 \%$ to $5.2 \%$, respectively. However, the GISS model projected a distinct decreasing trend of precipitation in the 2020s and 2080s for most of the study sites (Tingem et al., 2008c).

Agricultural production in Cameroon is characterised by low levels of input (e.g., quality seeds, fertilizers, pesticides and herbicides) due to farmers low purchasing power and equally low levels of government subsidies (Molua and Utomakili, 1998). Therefore, when considering projected climate change, one may reasonably ask whether Cameroonian farmers can continue farming in the same way that they have done for generations.

\section{MATERIALS AND METHODS}

\subsection{Crop model}

The crop model used in this study was CropSyst (Stöckle et al., 2003), a multi-year, multi-crop, daily time step cropping system simulation model. The model has been applied and used extensively to simulate crop growth and yield for a range of diverse crops such as rice (Confalonieri et al., 2006), maize (Tingem et al., 2008a) and cotton (Sommer et al., 2008), plus many other crops and environments. It has been used in detailed studies for both temperate and tropical crops and has been shown to be robust and accurate for a diverse range of local environments, including those found within Cameroon (Tingem et al., 2008b). It is a balanced crop simulator, simulating different crops from a common set of parameters and a single model structure. 
The model simulates the soil water budget, the soil-plant nitrogen budget, crop canopy and root growth, crop phenology, dry matter production, yield, residue production and decomposition, and erosion. The main inputs are daily weather data and the model allows the user to specify management options such as sowing date, cultivar coefficients such as photoperiod sensitivity, duration of grain filling and maximum leaf area index [LAI], soil profile properties including soil texture, thickness, initial water and nitrogen content, fertilizer and irrigation management and tillage. Crop growth is simulated for the whole canopy by calculating unstressed (potential) biomass based on crop potential transpiration and on crop intercepted photosynthetically active radiation. This potential growth is then corrected by water and nitrogen limitations, to determine actual daily biomass gain. The simulated grain yield is then obtained as the product between actual aboveground biomass accumulated at physiological maturity and crop-specific harvest index (harvestable yield/aboveground biomass).

The simulation of crop development is based on the thermal time required to reach specific development stages. Thermal time is calculated as growing degree days (GDD, ${ }^{\circ} \mathrm{C}$-days) accumulated throughout the growing season (starting from planting until physiological maturity). Average air temperature above a base and below a cut-off temperature is considered for growing degree day (GDD) calculations. The accumulation of thermal time may be accelerated by heat/water stress.

Water balance processes in CropSyst, includes rainfall, runoff, and interception, infiltration, redistribution in the soil profile, crop transpiration and soil evaporation. In this study, reference evapotranspiration was estimated by the Priestley and Taylor (1972) method. A finite difference solution soil water balance function, by which water moves up and down depending on the soil water potential of vertically adjacent layers, was used for the redistribution of water in the soil under non-limiting soil fertility (Richards, 1931).

CropSyst has data requirements that can be reasonably met and provides support utilities to fill in missing inputs based on well established procedures e.g. using pedo-transfer functions to derive soil hydraulic parameters. For this reason, it provides a conceptually unified modelling system for many crops, minimizing the dangers of structural uncertainty in making both cross crop and inter-spatial comparisons (Rivington et al., 2006). As such it is able to represent well the variation in yield determined by weather driven environmental conditions and respond to specific management regimen.

\subsection{Data sources and climate model}

Daily observed values of maximum and minimum temperatures, and rainfall were obtained for 1979-2003 from the University Cooperation for Atmospheric Research (UCAR) (http://dss.ucar.edu/datasets/) for each of the eight sites used in the study. For each region, the data from one of the major weather stations was chosen as representative of the climate of that region. For the purpose of evaluating long term effects of climate change and variability on crop yields, the temporal range of the weather data for use in the crop model was expanded up to 50 years so as to allow a good estimation of the probability of extreme events using the ClimGen weather generator. Further information on ClimGen performance at Cameroon sites is documented in Tingem et al. (2007)

Representative soil properties including thickness and texture for each of the simulation points were extracted from the International Soil Reference and Information Center data base (http://www.isric.nl) (Batjes, 1995). Agronomic data e.g. yield, phenological observations, were obtained from the Central Bureau of Statistics published district reports (AGRISTAT, 2001) and the Institute of Agricultural Research-Cameroon (through http://www.wisard.org).

The GISS model and HadCM3 model were used to simulate future climate scenarios. For the present-day (baseline) case, the weather generator ClimGen was parameterized to create a 50 -year baseline climate scenario from observed data at each site of study. For the future climate simulations, coupled GCMs (GISS and HadCM3) were used to simulate changes in climate and these changes were added to the baseline values to obtain the future climatic scenarios on a daily basis. The A2 scenario is one of the most extreme scenarios, with carbon emissions rising monotonically from about $10 \mathrm{Gt}$ at presentday to over $25 \mathrm{Gt}$ in 2100 (IPCC, 2001). The A2 scenario indicates the maximum potential impacts of future climate on specific dynamics, in this case crop production in the studied area. The B2 scenario is a more optimistic (medium-low) counterpart (Houghton et al., 1996).

\subsection{Simulation protocol and analyses}

The Parameterization of CropSyst for Cameroon agricultural regions is presented in Tingem et al. (2008a). Simulations were run with sowing dates set to 15 th March, corresponding to the 74th day of the year (DOY), in Bamenda, Batouri, Kribi Tiko, and Yaounde. In Garoua, Maroua and Ngaoundere, the sowing date was set to 15th May (day of year 135). The sowing date corresponds with traditional crop management in the study zones (Molua, 2003; Ndemah, 1999). A 1 m soil depth was considered to simulate the soil-water balance, because it corresponds to the observed maximum crop root length (Farre, 1998). Forty per cent of crop residue was assumed to remain in the field after harvest for recycling purposes (Abraha and Savage, 2006). No irrigation was used as this is not a common practice in Cameroon.

The effects of a $\mathrm{CO}_{2}$-induced climate change on crop production, expressed as the relative changes in yields between baseline and future 2020s/2080s climate are presented as percentage changes in average yields from the baseline. The yields and phenological maturity dates, simulated under the alternative climate scenarios were compared using exceedence probability $(P e, \%)$ distributions, following Weibull (1961):

$$
P e=\frac{m}{n+1} 100
$$

where $m$ is the rank order of each yield estimate, with $m=1$ as the largest and $m=n$ for the lowest, with $n$ being the number of observations. The coefficients of variation values 
of yield, defined as the ratio of standard deviation to the mean, were computed over the entire time-series available at each site. The \% coefficient of variation represents a measure of the farmer's risk, low coefficients indicate stable year-to-year production, while high coefficients denote high inter-annual variability (Rosenzweig and Tubiello, 2007).

Taking the "no regrets" principle (Hoffmann, 2007) into consideration, we explore the advantages of specific adaptation strategies specifically for three crops viz. maize, sorghum and bambara groundnut, under GISS A2 and B2 marker scenarios only. For clarity of interpretation, it is helpful to briefly explain how each adaptation strategy was implemented in the modelling framework. Sowing dates of selected crops were shifted by either bringing forward or delaying sowing within the interval $\left(D_{0-30}, D_{0-60}, D_{0+30}, D_{0+60}\right.$, days) with respect to the baseline case, $\mathrm{D}_{\mathrm{o}}$ being the normal sowing date.

Using CropSyst, growth performance of hypothetical cultivars under conditions of climate change was tested by adjusting the genetic coefficients of the currently used and calibrated cultivars in such a way that they would prolong the vegetative period under climate change conditions. Within CropSyst, the principal genetic parameter in question is the number of growing degree-days (GDDs) from flowering to maturity. A plant has a biological life that is determined by its GDDs or Heat Units (HUs). GDDs are a function of daily maximum and minimum air temperatures and the crop base temperature as shown in the following equation:

$$
G D D=\sum_{i=1}^{n}\left(T_{i}-T_{b}\right) \quad T_{i}=\mid \begin{aligned}
& T_{b} \text { if } T_{i}<T_{b} \\
& T_{c} \text { if } T_{i}>T_{c} \\
& \frac{T_{\max }+T_{\min }}{2} \text { otherwise }
\end{aligned}
$$

where $i$ is the $i$ th day from sowing, $T_{\max }$ and $T_{\min }\left({ }^{\circ} \mathrm{C}\right)$ are, respectively, the daily maximum and minimum air temperatures, and $T_{b}$ and $T_{c}\left({ }^{\circ} \mathrm{C}\right)$ are, respectively, crop-specific baseline and cut-off temperature for development (Ellis et al., 1990; McMaster and Wilhelm, 1997). To analyse the impact of GDD, the total temperature sum to maturity was increased arbitrarily between 15 and $20 \%$ and its effects on the length of the growing season and crop yield were recorded. The duration of vegetative relative to grain-filling periods in the original cultivar was maintained. Thus, the life cycle in terms of vegetativereproductive growth of the adapted crop under the warmer temperatures in both climate scenarios was comparable in length to that of the cultivars used for the baseline simulations. The use of nitrogen fertilization and irrigation are not considered in the study as these are non-limiting under all climate scenarios in studied sites.

\section{RESULTS AND DISCUSSION}

\subsection{Crop responses to future climate}

Nearly all future climate scenarios show a general tendency towards diminishing future maize yields in all agricultural regions; ranging between +27.1 to $-69.6 \%$ (Tab. I). Taking the mean over all regions, yield oscillated between -14.6 and $8.1 \%$ for GISS and between -8.2 and $15.7 \%$ for the HadCM3 model. The sorghum results appear to indicate that with the exception of the HadCM3 A2 and B2 2020s, $\mathrm{CO}_{2}$-induced climate change will result in either a substantial decrease or no change on sorghum crop yield, variable with location and scenario. Projections indicate substantial increases in the yield of groundnut by 21.5 to $109 \%$ from the baseline across all the scenarios in Batouri, Kribi, Maroua, Ngaoundere and Tiko. Simulated production in Bamenda decreased across all the scenarios by 11.9 to $41.6 \%$ except for HadCM3 A2 and B2 2020 where yields increase by $1.9 \%$. Scenario A2 2080s for both global circulation models produced a drop in yields at Garoua and Yaounde by 1.2 to $12.4 \%$. Bambara groundnut showed gains across all scenarios except for Tiko where a decrease by $5.1 \%$ was registered under GISS A2 2080s. Yield across all locations oscillated between 12.9 and $38.5 \%$. A substantial increase in soybean yields was generally estimated for the future. GISS and HadCM3 projected yield increases in the range 27.9 to $153.6 \%$ in 2020 s and 5.5 to $162.4 \%$ in 2080 s.

HadCM3 scenarios were more benign than the GISS scenarios, due to a smaller increase in air temperature. Higher temperatures translate into faster crop development and earlier maturation which results in lower crop yields because the plant intercepts less cumulative solar radiation before it reaches maturity and harvest (Young et al., 2000; Brassard and Singh, 2008; Rawson, 1992). The future climate scenarios used had maximum daily temperatures $>30^{\circ} \mathrm{C}$ on several days during the growing season especially with the GISS scenarios (Tingem et al., 2008c). The duration of the regular crop growing season for maize and sorghum ( $\mathrm{C} 4 \mathrm{crops})$ in the near future was simulated to be approximately between 2 to 29 days shorter than that under current climatic conditions resulting in a decrease in simulated grain yield for both. For groundnut, soybean and bambara groundnut (all $\mathrm{C} 3$ crops) the growing season was shortened by between 2 and 23 days. GISS and HadCM3 climate change scenarios projected increased yields for all the $\mathrm{C} 3$ crops above baseline levels across the whole country. In almost all cases, the negative effects of increased temperatures on crop duration were more than compensated by the positive effects of higher $\mathrm{CO}_{2}$ concentrations. These findings were obtained without considering a number of possible adaptations but when a range of adaptation techniques where implemented in CropSyst, crop yields were increased as detailed below.

\subsubsection{Sowings dates}

Advancing or delaying sowing dates led to increased yields (Tab. II) at Garoua, Maroua, Tiko and Yaounde. In Garoua and Maroua delaying sowing date resulted in better yields occurring on the 196th day of the year (DOY 196), corresponding to 15 th July. For Yaounde and Tiko sowing date was advanced to 15 th February (DOY 46).

Maize yields (Tab. IIa), under both GISS A2 and B2 scenarios increased up to $39.7 \%$, except for Maroua where yield was unchanged under B2 2080 and in Garoua under scenario 
Table I. Relative change (\%) in yield of five crops without adaptation between baseline and future climate projected under eight GCM scenarios. GCM: general circulation model.

\begin{tabular}{|c|c|c|c|c|c|c|c|c|}
\hline & \multicolumn{4}{|l|}{ GISS } & \multicolumn{4}{|c|}{ HadCM3 } \\
\hline & A2 2020 & A2 2080 & B2 2020 & B2 2080 & A2 2020 & A2 2080 & B2 2020 & B2 2080 \\
\hline \multicolumn{9}{|l|}{ Maize } \\
\hline Bamenda & -24.7 & -69.6 & -22.9 & -51.2 & -6.7 & -56.2 & -5.9 & -20.6 \\
\hline Batouri & 0.9 & -33 & 0.2 & -17.8 & 13.6 & -22.5 & 14.2 & -8.2 \\
\hline Garoua & 3.1 & -16.1 & 4.1 & -11 & 9.1 & -12.1 & 11.2 & -6.4 \\
\hline Kribi & 18.9 & 9.6 & 19.4 & 13.1 & 25.4 & 12.3 & 25.9 & 15.3 \\
\hline Maroua & 5.3 & -10.5 & 6.9 & -6.6 & 13.3 & -8.1 & 10.6 & -2.91 \\
\hline Ngaoundere & 24.6 & 6.2 & 25 & 17.3 & 27.1 & 13.8 & 26.9 & 22 \\
\hline Tiko & 12.6 & -0.6 & 12.5 & 3.5 & 18.3 & 3.4 & 18.4 & 7.6 \\
\hline Yaounde & 18.4 & -2.7 & 20 & 7.8 & 24.1 & 3.5 & 24.1 & 12.3 \\
\hline Mean & 7.4 & -14.6 & 8.2 & -5.6 & 15.5 & -8.2 & 15.7 & 2.4 \\
\hline \multicolumn{9}{|l|}{ Groundnut } \\
\hline Bamenda & -13.5 & -41.6 & -11.9 & -30.1 & 1.9 & -33.4 & 1.9 & -22.7 \\
\hline Batouri & 38.4 & 21.9 & 30.4 & 30.0 & 51.3 & 47.1 & 57.8 & 50.6 \\
\hline Garoua & 15.7 & -7.4 & 16.9 & 0.6 & 19.8 & -1.2 & 23.2 & 6.6 \\
\hline Kribi & 109.0 & 113.0 & 109.0 & 108.7 & 110.0 & 108.7 & 109.2 & 108.9 \\
\hline Maroua & 45.3 & 34.5 & 46 & 38.2 & 48.9 & 36.6 & 48 & 40.7 \\
\hline Ngaoundere & 50.3 & 37.2 & 51 & 41.7 & 57.2 & 40.1 & 57.1 & 44.5 \\
\hline Tiko & 19 & -1.8 & 25.6 & 12.1 & 35.2 & 16.8 & 32.3 & 21.5 \\
\hline Yaounde & 8.1 & -12.4 & 11.1 & -2.8 & 18.6 & -6.3 & 18.6 & 1.8 \\
\hline Mean & 34.0 & 17.9 & 34.8 & 24.8 & 42.9 & 26.1 & 43.5 & 31.5 \\
\hline \multicolumn{9}{|l|}{ Bambara } \\
\hline Bamenda & 31.2 & 1.2 & 32.9 & 17.3 & 42.5 & 13.2 & 43.3 & 23.5 \\
\hline Garoua & 24.3 & 4.9 & 25.2 & 11.9 & 31 & 10.2 & 30.1 & 16.8 \\
\hline Maroua & 37.2 & 25.9 & 37.8 & 29.5 & 41.3 & 28.2 & 40.4 & 32.1 \\
\hline Ngaoundere & 52.5 & 46.8 & 53.4 & 49.1 & 58.3 & 48.7 & 57.1 & 50.5 \\
\hline Tiko & 9.3 & -5.1 & 2 & 6.4 & 20.5 & 12.5 & 28.2 & 11.2 \\
\hline Yaounde & 21.5 & 3.9 & 24.6 & 12.8 & 31.6 & 9.6 & 31.6 & 16.8 \\
\hline Mean & 29.3 & 12.9 & 29.3 & 21.2 & 37.5 & 20.4 & 38.5 & 25.2 \\
\hline \multicolumn{9}{|l|}{ Sorghum } \\
\hline Garoua & -8.2 & -35.7 & -6.1 & -28.5 & 1.3 & -32 & 4.4 & -21.9 \\
\hline Maroua & 3.2 & -20.1 & 6.3 & -14.2 & 17.1 & -16.2 & 14.6 & -9.3 \\
\hline Ngaoundere & -16.6 & -63.8 & -12.3 & -47.8 & 3.8 & -53.5 & 3.4 & -40.7 \\
\hline Mean & -7.2 & -39.9 & -4.0 & -30.2 & 7.4 & -33.9 & 7.5 & -24.0 \\
\hline \multicolumn{9}{|l|}{ Soybean } \\
\hline Bamenda & 57.6 & 27.9 & 58.5 & 38.8 & 68.7 & 34.2 & 78.9 & 45.5 \\
\hline Ngaoundere & 27.9 & 5.5 & 29.6 & 12.6 & 39.5 & 10.9 & 39.5 & 18.8 \\
\hline Tiko & 126.9 & 130.4 & 127.7 & 134 & 153.6 & 148.2 & 145.5 & 162.4 \\
\hline Mean & 70.8 & 54.6 & 71.9 & 61.8 & 87.3 & 64.4 & 88.0 & 75.6 \\
\hline
\end{tabular}

GISS A2 2080. In the latter, yields are 3.8\% lower from the base case. Adverse climate change impacts on sorghum yields (Tab. IIb) are attenuated or even reversed at Garoua and Maroua when planting date was shifted from DOY D1 (May 15) to DOY D2 (July 15). While these adjustments increased yields by up to $48.0 \%$, however, average yield was still $17.3 \%$ and $7.5 \%$ lower from the base case at Garoua and Maroua under GISS A2 2080. Under GISS B2 2080 at Garoua, yields were still $14.2 \%$ lower from the baseline. Bambara groundnut (Tab. IIc), which was least affected by increasing temperatures, also responded positively to delayed dates, showing $19.7 \%$ to $48.3 \%$ increase in crop yields from the base case.

\subsubsection{Change in crop cultivar}

Adjusting growing degree days (GDDs) of bambara groundnut, maize and sorghum for hypothetical cultivars point to unequivocal gains in crop yields under different climate change scenarios across the entire country (Tab. III).

\section{Maize}

Average maize yields across the country increase, ranging from $32.1 \%$ to $62.3 \%$ (Tab. III) with decreasing coefficient of variation $(\mathrm{CV})$ ranging between 3.9 and $17.5 \%$ (Tab. IV). In Bamenda, yields increased by $22.3 \%$ to $95.9 \%$ in the early and 
Table II. Percent change in the average of maize (a), sorghum (b) and bambara (c) yields from baseline without and with adaptation (change in sowing dates) at Garoua (GAR), Maroua (MAR), Tiko (TIK) and Yaounde (YAO). GISS: Goddard Institute for Space Studies.

(a) Maize

\begin{tabular}{|c|c|c|c|c|c|c|c|c|}
\hline \multirow{4}{*}{ Location } & \multicolumn{4}{|c|}{$\begin{array}{c}\text { GISS without change in sowing } \\
\text { dates }\end{array}$} & \multicolumn{4}{|c|}{$\begin{array}{c}\text { GISS with change in sowing } \\
\text { dates }\end{array}$} \\
\hline & A2 & $\underline{\mathrm{A} 2}$ & $\underline{\mathrm{B} 2}$ & $\underline{\mathrm{B} 2}$ & $\underline{\mathrm{A} 2}$ & $\underline{\mathrm{A} 2}$ & $\underline{\mathrm{B} 2}$ & $\underline{\mathrm{B} 2}$ \\
\hline & $\underline{2020}$ & $\underline{2080}$ & $\underline{2020}$ & $\underline{2080}$ & $\underline{2020}$ & $\underline{2080}$ & $\underline{2020}$ & 2080 \\
\hline & $\% \Delta$ & $\% \Delta$ & $\% \Delta$ & $\% \Delta$ & $\% \Delta$ & $\% \Delta$ & $\% \Delta$ & $\% \Delta$ \\
\hline GAR & 3.1 & -16.1 & 4.1 & -11.0 & 24.5 & -3.8 & 26.6 & 5.7 \\
\hline MAR & 5.3 & -10.5 & 6.9 & -6.6 & 27.8 & 1.2 & 29.4 & -6.6 \\
\hline TIK & 12.6 & -0.6 & 12.5 & 3.5 & 26.4 & 16.3 & 28.8 & 20.1 \\
\hline YAO & 18.4 & -2.7 & 20.0 & 7.8 & 39.7 & 20.1 & 42.5 & 28.7 \\
\hline
\end{tabular}

(b) Sorghum

\begin{tabular}{|c|c|c|c|c|c|c|c|c|}
\hline \multirow{4}{*}{ Location } & \multicolumn{4}{|c|}{$\begin{array}{c}\text { GISS without change in sowing } \\
\text { dates }\end{array}$} & \multicolumn{4}{|c|}{$\begin{array}{l}\text { GISS with change in sowing } \\
\text { dates }\end{array}$} \\
\hline & $\underline{\mathrm{A} 2}$ & $\underline{\mathrm{A} 2}$ & $\underline{\mathrm{B} 2}$ & $\underline{\mathrm{B} 2}$ & $\underline{\mathrm{A} 2}$ & A2 & $\underline{\mathrm{B} 2}$ & $\underline{\mathrm{B} 2}$ \\
\hline & $\underline{2020}$ & $\underline{2080}$ & $\underline{2020}$ & 2080 & $\underline{2020}$ & $\underline{2080}$ & $\underline{2020}$ & $\underline{2080}$ \\
\hline & $\% \Delta$ & $\% \Delta$ & $\% \Delta$ & $\% \Delta$ & $\% \Delta$ & $\% \Delta$ & $\% \Delta$ & $\% \Delta$ \\
\hline GAR & -8.2 & -35.7 & -6.1 & -28.5 & 39.9 & -17.3 & 40.8 & 2.5 \\
\hline MAR & 3.2 & -20.1 & 6.3 & -14.2 & 48.0 & -7.5 & 51.5 & -14.2 \\
\hline
\end{tabular}

(c) Bambara groundnut

\begin{tabular}{|c|c|c|c|c|c|c|c|c|}
\hline \multirow{4}{*}{ Location } & \multicolumn{4}{|c|}{$\begin{array}{c}\text { GISS without change in sowing } \\
\text { dates }\end{array}$} & \multicolumn{4}{|c|}{$\begin{array}{c}\text { GISS with change in sowing } \\
\text { dates }\end{array}$} \\
\hline & $\mathrm{A} 2$ & $\mathrm{~A} 2$ & $\mathrm{~B} 2$ & B2 & $\mathrm{A} 2$ & $\underline{\mathrm{A} 2}$ & $\underline{\mathrm{B} 2}$ & B2 \\
\hline & $\underline{2020}$ & $\underline{2080}$ & $\underline{2020}$ & $\underline{2080}$ & $\underline{2020}$ & $\underline{2080}$ & $\underline{2020}$ & $\underline{2080}$ \\
\hline & $\% \Delta$ & $\% \Delta$ & $\overline{\% \Delta}$ & $\% \Delta$ & $\overline{\% \Delta}$ & $\% \Delta$ & $\overline{\% \Delta}$ & $\% \Delta$ \\
\hline GAR & 24.3 & 4.9 & 25.2 & 11.9 & 46.6 & 24.1 & 47.8 & 34.4 \\
\hline MAR & 37.2 & 25.9 & 37.8 & 29.5 & 48.1 & 39.3 & 48.3 & 29.5 \\
\hline TIK & 9.3 & -5.1 & 2 & 6.4 & 43.5 & 28.9 & 46.3 & 37.2 \\
\hline YAO & 21.5 & 3.9 & 24.6 & 12.8 & 37.9 & 19.7 & 41.7 & 28.9 \\
\hline
\end{tabular}

latter part of the 21st century. Simulated duration for the crop growing cycle was between 5 and 29 days longer compared to the growing season under base conditions (e.g. Figs. 1 and 2).

\section{Sorghum}

In the 2020s, average yield increased with adaptation by $38.3 \%$ to $155.7 \%$ and by $5.7 \%$ to $79.9 \%$ in the 2080 s under GISS projected climates (Tab. III). Interannual variability in both time periods also presents a remarkable stability in yields dropping in the range 19.4 to $11.1 \%$ (Tab. IV). Ngaoundere registered highest gains across all scenarios, i.e., $30.0 \%$ to $155.7 \%$ higher than baseline yields. Average relative yield increases across locations range from 17.6 to $89.5 \%$. With sorghum, the number of days from emergence to maturity increased across locations by 7 to 18 days.

\section{Bambara groundnut}

Substantial gains in yields were registered under this adaptation process. Increases in yield ranged from 11 to slightly more than 100 percent, and corresponding coefficient of variation (CV) dropped in the range 30.7 to $3.7 \%$ (Tabs. III, IV). Bamenda registered the highest increase in yields $(100.9 \%)$ under GISS A2 2020. Average yields in all growing sites in- creased by 37.1 to $55.4 \%$ while growing season increased by 5 to 13 days.

\subsection{Implications for policy}

Exploiting beneficial options to avoid or reduce negative effects of climate change is an imperative step in climatesensitive activities. The simulations presented above indicate that adjustments in sowing dates and use of late-maturing cultivars could produce substantial gains in crop yield under future climate change in Cameroon.

Advancing sowing dates by 30 days at Tiko and Yaounde, and delaying the same practice by 60 days at Garoua and Maroua for crops investigated would probably be the most appropriate response to offset the negative effects of a potential increase in temperature. Simply shifting sowing dates allows grown crops to develop under more favourable thermal conditions, increasing the duration of the vegetative phase, which in turn, would benefit the obtained grain number and hence the crop grain yield (Tab. V). However, this adaptive strategy only works well at some of the locations. This is because at some locations under the climate change scenarios low rainfall coupled with increased temperature span across the whole 
Table III. Yield changes for maize, sorghum and bambara groundnut without and with new cultivar (\% change from base). GISS: Goddard Institute for Space Studies.

\begin{tabular}{|c|c|c|c|c|c|c|c|c|}
\hline & \multicolumn{4}{|c|}{ GISS without adaptation } & \multicolumn{4}{|c|}{ GISS with adaptation } \\
\hline & $\underline{\mathrm{A} 2}$ & $\underline{\mathrm{A} 2}$ & $\underline{\mathrm{B} 2}$ & $\underline{\mathrm{B} 2}$ & $\underline{\mathrm{A} 2}$ & $\underline{\mathrm{A} 2}$ & $\underline{\mathrm{B} 2}$ & $\underline{\mathrm{B} 2}$ \\
\hline & 2020 & 2080 & 2020 & 2080 & $\underline{2020}$ & $\underline{2080}$ & $\underline{2020}$ & 2080 \\
\hline \multicolumn{9}{|l|}{ Maize } \\
\hline Bamenda & -24.7 & -69.6 & -22.9 & -51.2 & 93.2 & 22.3 & 95.9 & 59.6 \\
\hline Batouri & 0.9 & -33 & 0.2 & -17.8 & 62.9 & 23.4 & 61.8 & 42.3 \\
\hline Garoua & 3.1 & -16.1 & 4.1 & -11 & 49.8 & 22.5 & 52.9 & 30.5 \\
\hline Kribi & 18.9 & 9.6 & 19.4 & 13.1 & 61.4 & 49.8 & 62.4 & 53.9 \\
\hline Marou & 5.3 & -10.5 & 6.9 & -6.6 & 51.0 & 28.6 & 52.2 & 34.7 \\
\hline Ngaol & 24.6 & 6.2 & 25 & 17.3 & 63.8 & 43.8 & 64.4 & 54.9 \\
\hline Tiko & 12.6 & -0.6 & 12.5 & 3.5 & 49.8 & 34.5 & 50.7 & 40.1 \\
\hline Yaou & 18.4 & -2.7 & 20 & 7.8 & 55.9 & 31.7 & 57.8 & 44.3 \\
\hline Mean & 7.4 & -14.6 & 8.2 & -5.6 & 61.0 & 32.1 & 62.3 & 45.0 \\
\hline \multicolumn{9}{|l|}{ Sorghum } \\
\hline Garoua & -8.2 & -35.7 & -6.1 & -28.5 & 67.4 & 17.2 & 70.1 & 28.8 \\
\hline Mar & 3.2 & -20.1 & 6.3 & -14.2 & 38.3 & 5.7 & 42.8 & 14.9 \\
\hline Ngao & -16.6 & -63.8 & -12.3 & -47.8 & 149.0 & 30.0 & 155.7 & 79.9 \\
\hline Mean & -7.2 & -39.9 & -4 & -30.2 & 84.9 & 17.6 & 89.5 & 41.2 \\
\hline \multicolumn{9}{|l|}{ Bambara } \\
\hline Bamenda & 31.2 & 1.2 & 32.9 & 17.3 & 100.9 & 73.5 & 101.4 & 87.4 \\
\hline Garo & 24.3 & 4.9 & 25.2 & 11.9 & 40.9 & 19.3 & 41.9 & 27.2 \\
\hline Marc & 37.2 & 25.9 & 37.8 & 29.5 & 54.7 & 42.6 & 55.3 & 46.5 \\
\hline Ngaounder & 52.5 & 46.8 & 53.4 & 49.1 & 65.2 & 58.7 & 66.1 & 60.9 \\
\hline Tiko & 9.3 & -5.1 & 2 & 6.4 & 26.3 & 11.5 & 29.3 & 20.3 \\
\hline Yaour & 21.5 & 3.9 & 24.6 & 12.8 & 35.7 & 17.2 & 38.7 & 27.0 \\
\hline Mean & 29.3 & 12.9 & 29.3 & 21.2 & 53.9 & 37.1 & 55.4 & 44.9 \\
\hline
\end{tabular}

year- thus no space for favourable growth with changed sowing dates. This is in line with Rosenzweig (1989) who found that altering sowing dates for dry land maize in the Southern plains of USA offset yield reduction caused by climate change at only one of the 12 locations while the other 11 locations continued to show yield reductions. Simulation results suggest that gains made from shifting sowing dates are irrelevant to offset negative changes when high temperatures affect early and later growth phases of the crops.

From simulation results, one of the most influential factors determining yield under the changed climatic conditions is an increase in temperature. High temperatures speed up phenological development of crops and leave less time for the grain/seed formation. The optimum adaptive response to increasing temperatures (i.e., global warming) in Cameroon where adjusting planting dates does not shield crops from the effects of higher temperature, would be to develop and replace currently used cultivars with those with a higher thermal requirements for completion of phenological stages. Mimicking the outcome of selective breeding and genetic engineering programmes, we made changes in CropSyst genotypic parameters driving the phenological development of maize, sorghum and bambara groundnut. Simulations based on these changes led to significant increases in crop yields. This is in agreement with simulation results reported by Kaiser et al. (1993), Reilly and Schimmelpfenning (1999), and Butt et al. (2005).

Whereas simulation results for C3 crops showed substantial gains under climate change without any adaptation (2020s,
Table IV. Coefficient of variation (CV) of maize, sorghum and bambara groundnut yields without and with new cultivar (\% change from base). GISS: Goddard Institute for Space Studies.

\begin{tabular}{|c|c|c|c|c|c|c|c|c|}
\hline & \multicolumn{4}{|c|}{ GISS without adaptation } & \multicolumn{4}{|c|}{ GISS with adaptation } \\
\hline & A2 & $\underline{\mathrm{A} 2}$ & $\underline{\mathrm{B} 2}$ & $\underline{\mathrm{B} 2}$ & A2 & $\mathrm{A} 2$ & B2 & B2 \\
\hline & $\underline{2020}$ & $\underline{\underline{2080}}$ & $\underline{2020}$ & $\underline{2080}$ & $\underline{2020}$ & $\underline{2080}$ & $\underline{2020}$ & $\underline{2080}$ \\
\hline \multicolumn{9}{|c|}{ 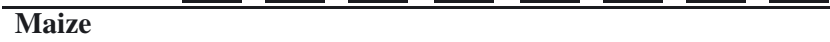 } \\
\hline Bamenda & 19.7 & 21.1 & 19.8 & 22.9 & 10.9 & 13.4 & 10.6 & 12.7 \\
\hline Batouri & 10.4 & 18.8 & 16.8 & 12.3 & 16.8 & 15.5 & 17.5 & 14.2 \\
\hline Garoua & 7.9 & 9.5 & 7.8 & 9.2 & 8.8 & 8.5 & 7.8 & 8.9 \\
\hline Kribi & 7.9 & 8.6 & 8.2 & 7.5 & 6.8 & 7.5 & 6.8 & 6.6 \\
\hline Maroua & 8.5 & 6.4 & 8.9 & 7.3 & 7.7 & 7.1 & 7.8 & 7.7 \\
\hline Ngaoundere & 4.3 & 3.5 & 5.0 & 4.3 & 4.4 & 3.9 & 4.3 & 4.1 \\
\hline Tiko & 5.2 & 5.6 & 4.9 & 5.1 & 5.1 & 5.0 & 4.9 & 4.5 \\
\hline Yaounde & 6.2 & 7.0 & 6.2 & 7.5 & 5.9 & 6.7 & 6.1 & 7.0 \\
\hline Mean & 8.8 & 10.1 & 9.7 & 9.5 & 8.3 & 8.4 & 8.2 & 8.2 \\
\hline \multicolumn{9}{|l|}{ Sorghum } \\
\hline Garoua & 16.4 & 12.7 & 16.9 & 13.9 & 14.3 & 12.2 & 14.3 & 13.2 \\
\hline Maroua & 17.8 & 14.6 & 16.2 & 16.9 & 17.3 & 13.6 & 15.4 & 16.6 \\
\hline Ngaoundere & 18.7 & 19.5 & 17.9 & 20.4 & 11.5 & 19.4 & 11.1 & 17.4 \\
\hline Mean & 17.6 & 15.6 & 17.0 & 17.1 & 14.4 & 15.1 & 13.6 & 15.7 \\
\hline \multicolumn{9}{|l|}{ Bambara } \\
\hline Bamenda & 7.3 & 21.9 & 6.9 & 7.4 & 4.9 & 12.4 & 4.8 & 5.2 \\
\hline Garoua & 4.3 & 4 & 4.3 & 4 & 3.8 & 3.9 & 3.8 & 3.7 \\
\hline Maroua & 7.5 & 7.6 & 7.5 & 7.5 & 7.1 & 7.3 & 7.1 & 7.2 \\
\hline Ngaoundere & 7 & 7.6 & 6.8 & 7.3 & 6.0 & 7.7 & 6.4 & 7.3 \\
\hline Tiko & 29.1 & 26.5 & 39.8 & 25.3 & 30.5 & 26.5 & 30.7 & 26.4 \\
\hline Yaounde & 8.3 & 8.5 & 8.2 & 8.5 & 7.8 & 8.3 & 8.6 & 8.3 \\
\hline Mean & 10.6 & 12.7 & 12.3 & 10.0 & 10.0 & 11.0 & 10.2 & 9.7 \\
\hline
\end{tabular}

2080s), using a new cultivar, yields of bambara groundnut (an under-researched and underutilised African legume) were almost trebled due to increase length of growing period and the positive effects of higher $\mathrm{CO}_{2}$ concentrations. These results highlight the need to search for and promote new crop options as well as practices and methods that make maximum utilization of prevalent crop and climatic combinations.

Using this modelling framework, policy support for potential crop adaptation to climate change through breeding for late-maturing and more heat-tolerant cultivars can be explored and pursued in a rigorous manner. It is relatively simple to measure physiological parameters using modern apparatus and new analytical tools (Araus et al., 2002; FAO, 2007). However, to develop a new crop variety takes up to a decade and might entail using a combination of new technologies such as genetic engineering and marker-assisted selection. Currently, there is no evidence of focused efforts for developing such cultivars even for major crops in Cameroon. With this in mind, and using the findings of this research, international donor agencies working in Cameroon and plant breeders could undoubtedly take up the challenge of developing late-maturing-more productive cultivars that might better suit the climate change scenarios for Cameroon.

Important policy implications can be drawn from the analysis presented in this study. Development of new crop cultivars appears to be an important policy option to make agriculture in 

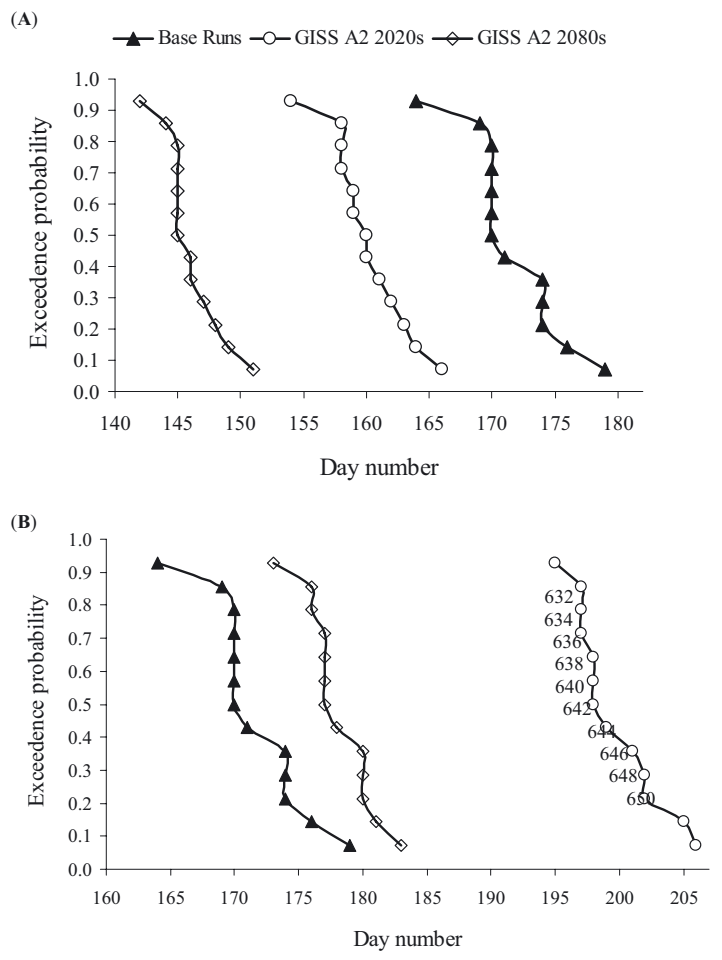

Figure 1. Effects of adaptation (new cultivar) on number of days to maturity in maize at Bamenda: (A) base runs together with GISS A2 scenarios without adaptation (B) GISS A2 scenarios with adaptation. GISS: Goddard Institute for Space Studies.
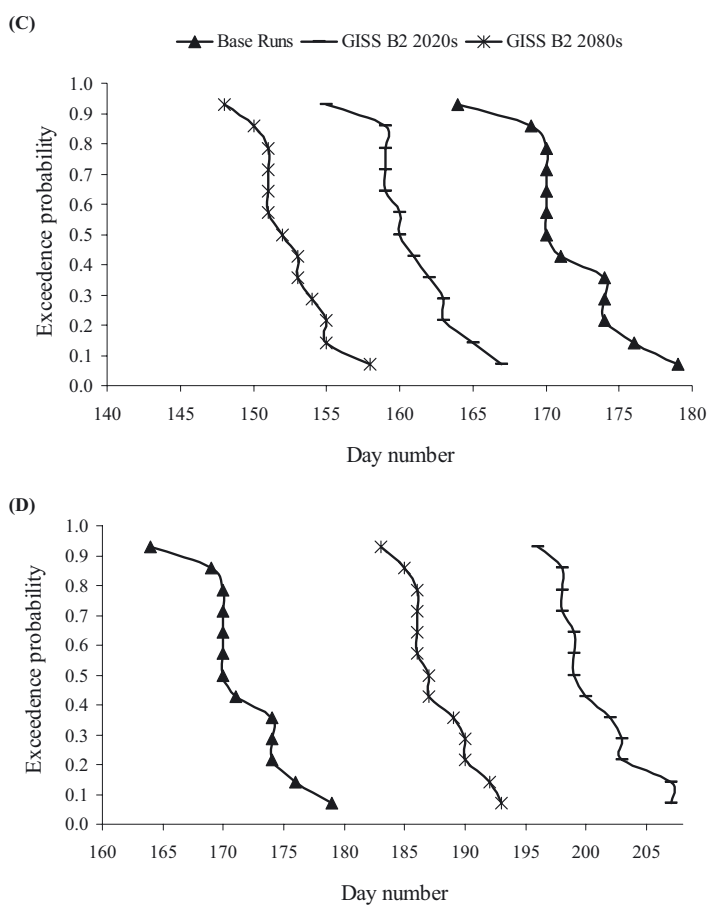

Figure 2. Effects of adaptation (new cultivar) effects on number of days to maturity in maize at Bamenda: (C) base runs together with GISS B2 scenarios without adaptation (D) GISS B2 scenarios with adaptation. GISS: Goddard Institute for Space Studies.
Table V. Length (days) of planting to flowering (P-F) and flowering to maturity $(\mathrm{F}-\mathrm{M})$ periods for maize at current planting date and 30 days earlier under SRES A2 scenario for year 2020 at Yaounde.

\begin{tabular}{lccc}
\hline & \multicolumn{2}{c}{ Current } & \multicolumn{2}{c}{ Thirty days before } \\
\cline { 2 - 4 } P-F & BASE & GISS A2 2020 & GISS A2 2020 \\
\cline { 2 - 4 } F-M & 62 & 57 & 76 \\
\hline
\end{tabular}

Cameroon more resilient to climate change. The past experience in developing countries suggests that a wider adoption of new genotypes may take more than a decade (Kurukulasuriya et al., 2006) and may also require effective promotional campaigns. An early start on the development and adoption of these genotypes is therefore imperative.

The costs of breeding new cultivars are uncertain but likely to be substantial and beyond the economic capacity of any single developing country such as Cameroon. Such strategies must be seen in the broader context of global environment governance under the UNFCCC and its Kyoto protocol. The results of this research may be used for countries like Cameroon to not only raise their voices for $\mathrm{CO}_{2}$ abatement but also seek support from developed countries in the form of technology transfer, food aid, and flow of financial resources addressing Article 4.4 of UNFCCC which commits developed country parties to "assist developing country parties that are particularly vulnerable to the adverse effects of climate change...".

\section{CONCLUSION}

We investigated the adaptation options which could offset climate change impacts on Cameroon's agriculture. The results show that sowing dates may not be very effective in mitigating the adverse effects of climate change. However, the use of new crop cultivars with specific genetic traits was found most effective in reducing the adverse effects. Sizable differences between improved and current cultivars, indicates that promoting late-maturing/heat-tolerant cultivars could help alleviate the likely effects of climate change in Cameroon. Thus, a combination of rigorous research and outreach programmes, and investment in improved technology are required to demonstrate and promote use of varieties with more tolerance for the future climate. Such findings present a wake-up call for policy planners and the research community in Cameroon and elsewhere.

Acknowledgements: We acknowledge the help and assistance provided by Claudio O. Stöckle and Roger L. Nelson (Biological Systems Engineering Department, Pullman WA, USA) in using CropSyst and ClimGen. Climate change scenarios were provided by the NASA/Goddard Institute for Space Studies (New York City, USA), thanks to Richard Goldberg and Cynthia Rosenzweig. Contributions by Momodou Njie are also highly acknowledged.

\section{REFERENCES}

Abraha M.G., Savage M.J. (2006) Potential impacts of climate change on the grain yield of maize for the midland of Kwazulu-Natal, South Africa, Agr. Ecosyst. Environ. 115, 150-160. 
Adger W.N., Arnell N.W., Tompkins E.L. (2005) Successful adaptation to climate change across scales, Global Environ. Chang. 15, 77-86.

AGRISTAT (2001) Semi-annual bulletin of the statistics of agricultural sector 2000/2001, DEPA, Ministry of Agriculture, Cameroon.

Alexandrov V.A., Hoogenboom G. (2000) The impact of climate variability and change on crop yield in Bulgaria, Agr. Forest Meteorol. 104, 315-327.

Araus J.L., Slafer G.A., Reynolds M.P., Royo C. (2002) Plant Breeding and Drought in C3 Cereals: What Should We Breed For? Ann. Bot. 89, 925-940.

Asseng S., Van Herwaarden A., Setter T.L., Palta J.A. (2003) The impact of crop modelling on plant physiological research and breeding an example, in: Solutions for a better environment, Proceedings of the 11th Australian Agronomy Conference, Geelong, Victoria, Australia, 2-6 February 2003, Published on CDROM ISBN 0-9750313-0-9, 4 p.

Batjes N. (1995) A homogenised soil data file for global environmental research: a subset of FAO, ISRIC and NRCS profiles (version 1.0). Working paper 95/10. International Soil Reference Information Center (ISRIC), Wageninger, The Netherlands.

Bellocchi G., Maestrini C., Fila G., Fontana F. (2002) Assessment of the effects of climate change and elevated $\mathrm{CO}_{2}$ : a case study in Northern Italy, VII European Society for Agronomy Congress, Cordoba, Spain, 15-18 July 2002, pp. 763-764.

Brassard J., Singh B. (2008) Impacts of climate change and $\mathrm{CO}_{2}$ increase on agricultural production and adaptation options for Southern Québec, Canada, Mitigation and Adaptation Strategies for Global Climate Change 13, 241-265.

Butt T.A., MCcarl B.A., Angerer J., Dyke P.T., Stuth J.W. (2005) The Economic and food security implications of climate change in Mali, Climatic Change 68, 355-378.

Carbone G.J., Kiechle W., Locke C., Mearns L.O., McDaniel L., Downton M.W. (2003) Response of soybean and Sorghum to varying spatial scales of climate change scenarios in the South-eastern United States, Climatic Change 60, 73-98.

Challinor A.J., Wheeler T.R., Craufurd P.Q., Ferro C.A.T., Stephenson D.B. (2007a) Adaptation of crops to climate change through genotypic responses to mean and extreme temperatures, Agr. Ecosyst. Environ. 119, 190-204.

Challinor A.J., Wheeler T.R., Garforth C., Craufurd P.Q., Kassam A. (2007b) Assessing the vulnerability of food crop systems in Africa to climate change, Climatic Change 83, 381-399.

Confalonieri R., Gusberti D., Bocchi S., Acutis M. (2006) The CropSyst model to simulate the $\mathrm{N}$ balance of rice for alternative management, Agron. Sust. Dev. 26, 241-249.

Ellis R.H., Hadley P., Roberts E.H., Summerfield R.J. (1990) Relations between temperature and crop development, in: Jackson M.M., Ford-Lloyd B.V., Parry M.L. (Eds.), Climatic Change and Plant Genetic Resource, Belhaven Press, London pp. 85-115.

FAO (2007) Marker-Assisted Selection, in: Guimarães E.P., Ruane J., Scherf B.D., Sonnino A., Dargie J.D. (Eds.), Current status and future perspectives in crops, livestock, forestry and fish (available at ftp://ftp.fao.org/docrep/fao/010/a1120e/a1120e.pdf), Rome.

Farre I. (1998) Maize (Zea mays L.) and Sorghum (sorghum bicolor L. Moench) response to deficit irrigation. Agronomy and Modelling, $\mathrm{PhD}$ Dissertation, University of Lieida, Spain, $150 \mathrm{p}$.

Gbetibouo G.A., Hassan R. (2004) Measuring the economic impact of climate change on major South African filed crops: a Ricardian approach, Global Planet. Change 47, 143-152.

Gordon C., Cooper C., Senior C.A., Banks H., Gregory J.M., , Johns T.C., Mitchell J.F.B., Wood R.A. (2000) The Simulation of SST, sea ice extents and ocean heat transports in a version of the Hadley Centre coupled model without flux adjustments, Clim. Dynam. 16, 147168.

Hansen J.E., Sato M.K.I., Lacis A., Ruedy R., Tegen I., Matthews E. (1998) Perspective: Climate forcings in the industrial era, Proc. Natl Acad. Sci. USA 95, 12753-12758.

Hoffmann M.J. (2007) Contesting the Global Response to Climate Change: A Research Agenda for Examining Experiments in Climate Governance. Amsterdam Conference on the Human Dimensions of Global Environmental Change, 24-26 May 2007, Vrije Universiteit Amsterdam, 2 p.

Houghton J., Meira L.G., Callander B.A., Harris N., Kattenberg A., Maskell K. (Eds.) (1996) The Science of Climate Change (Vol. 1), The second assessment Report of IPCC, $570 \mathrm{p}$.

IPCC (2001) Climate change 2001: Impacts, Adaptation, and Vulnerability, a contribution of working group II to the Third assessment Report of the IPCC, Cambridge University Press, $1032 \mathrm{p}$.

IPCC (2007) Climate Change 2007: The Physical Science Basis. Contribution of Working Group I to the Fourth Assessment Report of the Intergovernmental Panel on Climate Change, in: Solomon S., Qin D., Manning M., Chen Z., Marquis M., Averyt K.B., Tignor M., Miller H.L. (Eds.), Cambridge University Press, Cambridge, United Kingdom and New York, NY, USA, 996 p.

Johns T.C., Gregory J.M., Ingram C.E., Johnson C.E., Jones A., Lowe J.A., Mitchell J.F.B., Roberts D.L., Sexton D.M.H., Stevenson D.S., Tett S.F.B., Woodage M.J. (2003) Anthropogenic climate change for 1860-2100 simulated with the HadCM3 model under updated emissions scenarios, Clim. Dynam. 20, 583-612.

Kaiser H.M., Riha S.J., Wilks D.S., Rossier D.G., Sampath R. (1993) A farm-land analysis of economic and agronomic impacts of global warming, Am. J. Agr. Econ. 75, 263-286.

Kurukulasuriya P., Mendelsohn R., Hassan R. (2006) Will African Agriculture Survive Climate Change, World Bank Econ. Rev. 20 367-388.

McCarthy J.J., Canziani O.F., Leary N.A., Dokken D.J., Kasey S.W. (Eds.) (2001) Climate Change 2001: Impacts, Adaptation and Vulnerability. Contribution of Working Group II to the IPCC Third Assessment Report. Cambridge University Press, Cambridge, UK, $1032 \mathrm{p}$.

McMaster G.S., Wilhelm W.W. (1997) Growing degree-days: one equation, two interpretations, Agr. Forest Meteorol. 87, 291-300.

Mendelsohn R., Nordhaus W.D., Shaw D. (1994) The impacts of climatic change on agriculture: a Ricardian analysis, Am. Econom. Rev. 84, $753-771$

Molua E.L. (2003) Global climate change and Cameroon's Agriculture: evaluating the economic impacts, $\mathrm{PhD}$ dissertation In Institute of Agricultural Economics, Vol. PhD, 199 Goettingham: GeorgAugust University, Germany, 94 p.

Molua E.L. (2006) Climate trends in Cameroon: implications for agricultural management, Climate Res. 30, 255-262.

Molua E.L., Lambi C.M. (2006) The economic impact of climate change on agriculture in Cameroon. CEEPA Discussion paper No. 17, Centre for Environmental Economics and Policy in Africa, University of Pretoria.

Molua E.L., Utomakili J.B. (1998) An Analysis of Resource-Use Efficiency in Banana Production in the South West Province of Cameroon, Int. J. Trop. Agr. 16, 113-118.

Ndemah R.N. (1999) Towards an integrated crop management strategy for the African stalk borer Busseola fusca (Fuller) (Lepidoptera: Noctuidae) in maize systems in Cameroon, $\mathrm{PhD}$ Thesis, University of Hannover, Hannover, Germany, 145 p. 
Njie M., Gomez M.E.H., Callaway J.M., Jallow B.P., Droogers P. (2006) Making Economic Sense of Adaptation in the Upland Cereal Production Systems in the Gambia, AIACC Working Paper No. 37.

Onduru D.D., Du Preez C.C. (2007) Ecological and agro-economic study of small farms in sub-Saharan Africa, Agron. Sust. Dev. 27, 197208.

Priestley C.H.B., Taylor R.J. (1972) On the assessment of surface heat flux and evaporation using large-scale parameters, Mon. Weather Rev. 100, 81-82.

Rawson H.M. (1992) plant responses to temperature under conditions of elevated $\mathrm{CO}_{2}$, Aust. J. Bot. 40, 473-490.

Reilly J. (1995) Climate change and global agriculture: Recent findings and issues, Am. J. Agr. Econ. 77, 727-733.

Reilly J., Schimmelpfenning D. (1999) Agricultural impact assessment, vulnerability, and the scope for adaptation, Climatic Change 43, 745-788.

Richards L.A. (1931) Capillary conduction of liquids in porous mediums, Phys. 1, 318-333.

Rivington M., Matthews K.B., Bellocchi G., Buchan K., Stöckle C.O., Donatelli M. (2006) An integrated assessment approach to conduct analyses of climate change impacts on whole-farm systems, Environ. Modell. Softw. 22, 202-210.

Rosenzweig C. (1989) Potential Effects of Climate Change on Agricultural Production in the Great Plains: A simulation Study, in: Smith J., Tirpak D. (Eds.), The potential effects of global climate change on the United States, Vol. 1, Appendix C, Office of Policy, Planning and Evaluation, U.S. Environmental Protection Agency, Washington, DC, pp. 3-43.

Rosenzweig C., Hillel D. (1998) Climate change and the global harvest, in PBD: 1998, 323 p.; PL: United States: Oxford University Press, New York, NY.

Rosenzweig C., Iglesias A., Yang X., Epstein P., Chivian E. (2001) Climate change and extreme weather events: implication for food production, plant diseases and pest, Global Change Human Health $2,90-104$.

Rosenzweig C., Tubiello F.N. (2007) Adaptation and mitigation strategies in agriculture: an analysis of potential synergies, Mitigation and Adaptation Strategies for Global Climate Change 12, 855-873.

Salinger M.J., Stigter C.J., Das H.P. (2000) Agro meteorological adaptation strategies to increasing climate variability and climate change, Agr. Forest Meteorol. 103, 167-184.
Sommer R., Kienzler K., Conrad C., Ibragimov N., Lamers J., Martius C., Vlek P. (2008) Evaluation of the CropSyst model for simulating the potential yield of cotton, Agron. Sustain. Dev. 28, 345-354.

Smith B., Skinner M. (2002) Adaptation options in agriculture to climate change: a topology, Mitigation and Adaptation Strategies for Global Climate Change 7, 85-114.

Smith B., Wandel J. (2006) Adaptation, adaptive capacity and vulnerability, Global Environ. Chang. 16, 282-292.

Stöckle C.O., Donatelli M., Nelson R. (2003) CropSyst, a cropping systems simulation model, Eur. J. Agron. 18, 289-307.

Tingem M., Rivington M., Azam Ali S.N., Colls J.J. (2007) Assessment of the ClimGen stochastic weather generator at Cameroon sites, Afr. J. Environ. Sci. Technol. 1, 86-92.

Tingem M., Rivington M., Bellocchi G., Colls J.J. (2008a) Crop Yield Model Validation for Cameroon, Theor. Appl. Climatol., doi: 10.1007/s00704-008-0030-8.

Tingem M., Rivington M., Azam Ali S.N., Colls J.J. (2008b) Climate variability and maize production in Cameroon: simulating the effects of extreme dry and wet years, Singapore J. Trop. Geogr., in press.

Tingem M., Rivington M., Bellocchi G., Azam-Ali S., Colls J. (2008c) Effects of climate change on crop production in Cameroon, Climate Res. 36, 65-77.

Walther G., Convey P., Menzel A., Parmesank C., Beebee T., Fromentin J., Hoegh-Guldberg O., Bairlein F. (2002) Ecological responses to recent climate change, Nature 416, 389-395.

Weibull W. (1961) Fatigue testing and analysis of results, Pergamon Press Oxford, United Kingdom, 225 p.

Winters P., Murgai R., Sadoulet E., De Janvry A., Frisvold G. (1998) Economic and Welfare Impacts of climate change on Developing Countries, Environ. Resource Econ. 12, 1-24.

World Bank (2007) World Development Indicators Database [avaliable at http://devdata.worldbank.org/ accessed on 24 July 2007].

Young K.J., Long S.P., Allen L.H.J., Boote K.J. (2000) Crop ecosytem response to climatic change: maize, sorghum and soybean, in: Reddy K.R., Hodges H.F. (Eds.), Climate Change and Crop Productivity, CAB International Cambridge, pp. 57-80. 